\title{
Retraction Note: The concept of environmental protection in marine oil pollution and political teaching based on image deblurring method
}

Li Sun ${ }^{1}$

Published online: 3 November 2021

(c) Saudi Society for Geosciences 2021

Arabian Journal of Geosciences (2021) 14: 1620

https://doi.org/10.1007/s12517-021-07857-y

The Editor-in-Chief and the Publisher have retracted this article because the content of this article is nonsensical. The peer review process was not carried out in accordance with the Publisher's peer review policy. The author has not responded to correspondence regarding this retraction.

The original article can be found online at https://doi.org/10.1007/ s12517-021-07857-y.

\section{Li Sun}

s120212021@163.com

1 School of Marxism, Nanchong Vocational and Technical College, Nanchong 637000, Sichuan, China 